\title{
Analysis of $(\mathrm{Cr}, \mathrm{Mo})$ Oxycarbide Films Grown on Stainless Steel via Metalloorganic Chemical Vapor Deposition
}

\author{
Ming-Hung Lo and Wen-Cheng J. Wei \\ Institute of Materials Science and Engineering, National Taiwan University, \\ Taipei, Taiwan 106, Republic of China
}

\begin{abstract}
A mixture of hexacarbonyl of chromium and molybdenum $\left((\mathrm{Cr}, \mathrm{Mo})(\mathrm{CO})_{6}\right)$ was used to deposit oxycarbide films on stainless steel at temperatures of $175^{\circ}-450^{\circ} \mathrm{C}$. Through the analysis of deposition kinetics in various temperature regions, the controlling mechanism was determined to be exothermic surface reactions. Activation energies of the low- and medium-temperature regions were determined to be 71.2 and $-60.1 \mathrm{~kJ} / \mathrm{mol}$, respectively. Some propertiesincluding densities, composition, and crystalline phasesof the films were investigated. Results revealed that the chromium content of coating products increased as the temperature increased. The dominating surface reactions switched as temperature increased, because of the increase of chromium content in the precursor gas. Hence, the coating rate and density increased to a maximum, then decreased as the coating temperature was increased to $.275^{\circ} \mathrm{C}$. Deposited phases were determined by $\mathrm{X}$-ray diffractometry, and the relationship with film density phases has been discussed, using their microstructural textures from scanning electron microscopy micrographs. Corrosion resistance was measured by an electrochemical method. The films obtained in the low- and medium-temperature regions improved the corrosion resistance of stainless-steel substrates by a factor of 24 . In addition, the latter case showed the effect of passive protection and was an optimized selection for corrosive protection. The relationship of the improvement of corrosion resistance, physical properties, and the contribution of composed phases was discussed.
\end{abstract}

\section{Introduction}

$\mathrm{M}$ ETALLOORGANIC chemical vapor deposition (MOCVD) is widely used in the production of semiconductive film. ${ }^{1-3}$ One advantage of this method is processing at low temperatures. Therefore, a refractory substrate is not needed. Oxidation or other unwanted reactions also are avoided. ${ }^{4}$ Stress that is induced by the thermal mismatch between the film and the substrate may thereby be reduced and overcome.

Various types of films, including alloys, oxides, and nitrides, can be deposited from the mixture of several reactant gases. ${ }^{5}$ Numerous researchers have investigated the formation of films of refractory metals via pyrolysis or photolysis of metalloorganic compounds. ${ }^{6-9}$ These films were usually deposited for microelectronics, e.g., for interconnection or conductive purposes for high-temperature applications.

Chloride and sulfur acidic ions have been proven to be detrimental to stainless steels, e.g., SS 304, in their interaction with the corrosive environment. ${ }^{10}$ Recently, the formation of

T. M. Besmann—contributing editor

Manuscript No. 192322. Received September 19, 1995; approved October 14, 1996 Research funding by the National Science Council, under Contract No. NSC852216-E-002-019.

"Member, American Ceramic Society. corrosion-resistant alloy on the surface of $\mathrm{Fe}-\mathrm{Cr}$ alloy has been studied using ion implantation with $\mathrm{Cr}^{+}+\mathrm{Mo}^{+}$or $\mathrm{Mo}^{+}$ions. Surface alloys containing molybdenum and chromium have been reported and proven to be effective for sulfuric acid corrosion resistance. ${ }^{11,12}$ However, the cost of the instruments and low productivity of the ion implantation process have restricted its application. ${ }^{13}$ Therefore, films formed from a mixture of metalloorganics of molybdenum and chromium via pyrolysis or photolysis offer a potential application for corrosive resistance.

Improvement of corrosion resistance by using chemical vapor deposition (CVD) from the mixture of chromium and molybdenum hexacarbonyl, $\mathrm{Cr}(\mathrm{CO})_{6}$ and $\mathrm{Mo}(\mathrm{CO})_{6}$, respectively, with an excimer laser has been studied; ${ }^{14}$ however, the laser generator is quite expensive. Also, a laser-induced chemical vapor deposition (LICVD) cannot perform a long-term deposition, because of the obstruction of the laser beam from the simultaneous deposition on the window. Therefore, MOCVD is regarded as a better choice without such disadvantages. However, no such studies have been performed to investigate the improvement of corrosion resistance of films that are prepared by MOCVD.

Characteristics of films formed by MOCVD or similar methods are deeply affected by the kinetic state of the coating condition. Because of the fact that coated films are formed in a quasi-steady state, phases and chemical compositions will vary with the kinetic state under which they are prepared. Therefore, discussion of the kinetic state and, hence, the determination of the controlling mechanism are interesting.

The decomposition points of $\mathrm{Mo}(\mathrm{CO})_{6}$ and $\mathrm{Cr}(\mathrm{CO})_{6}$ are reported to be $\sim 150^{\circ} \mathrm{C}$ and $154^{\circ} \mathrm{C},{ }^{15}$ respectively. In all the laboratory work, ${ }^{6,7,16,17}$ the coated layer was deposited at temperatures of $>300^{\circ} \mathrm{C}$. The coated layer at a temperature of $<300^{\circ} \mathrm{C}$ and its properties were not investigated. Therefore, we extended our attention to the films that were prepared at temperatures of $<300^{\circ} \mathrm{C}$. The compositions, phases, and relative properties of the coated layers that varied with the processing temperature also are systematically investigated.

In this study, a mixture of $\mathrm{Mo}(\mathrm{CO})_{6}$ and $\mathrm{Cr}(\mathrm{CO})_{6}$ was used to deposit films on stainless steel at various temperatures of $<450^{\circ} \mathrm{C}$. The coating rate was plotted as a function of temperature. Determination of the controlling mechanism via the discussion on the diffusion flux and activation energy of the serial steps of the coating process was accomplished. Composition, crystalline phases, and thickness of the films obtained at various temperatures were identified by using X-ray photoemission spectroscopy (XPS), X-ray diffractometry (XRD), and scanning electron microscopy (SEM), respectively. Corrosion resistance of the stainless steel with and without coated films in a testing medium with chlorides and sulfuric acid was evaluated, as a function of the coating properties, by an electrochemical method.

\section{Experimental}

\section{(1) Substrate Preparation}

Stainless steel 304 substrates were sliced from a plate with a thickness of $1 \mathrm{~mm}$ to a square shape $5 \mathrm{~mm} \times 5 \mathrm{~mm}$. The 
thermal gradient between the two surfaces of the substrate is minimized by reducing the thickness. These substrates were ground, then polished with alumina slurry $(0.3 \mu \mathrm{m})$ to yield smooth surfaces, one surface being for the deposition of film and the other being for the attachment of the thermocouple. After polishing, the thickness of the substrates was $<0.8 \mathrm{~mm}$. Polished substrates were then cleaned thoroughly several times with acetone in an ultrasonic bath. In the last step before coating, the substrates were put into a vacuum vessel that was pumped to a pressure of $\sim 1.3 \mathrm{~Pa}$ (0.01 torr) and left overnight.

\section{(2) Coating Operation}

A mixture of $\mathrm{Mo}(\mathrm{CO})_{6}$ and $\mathrm{Cr}(\mathrm{CO})_{6}$ (Strem Chemicals Co., Newburyport, MA) was put in a source chamber and carried by $\mathrm{N}_{2}$ gas that was controlled at $6 \mathrm{~mL} / \mathrm{min}$ with a flow meter. The mass fraction of $\mathrm{Cr}(\mathrm{CO})_{6}$ in the mixture was $0.10(\sim 12 \%$ in molar ratio). The gaseous mixture flowed into one side of the reaction chamber (tube) while the other side of the reaction chamber was connected to two outlets: one for an absolute pressure gauge with a variable-capacitance sensor (Type 122A, MSK Baratron, Andover City, MA), and the other for a rotary pump. The chamber was first emptied to greater than $\sim 0.13 \mathrm{~Pa}$ $\left(>10^{-3}\right.$ torr) before introducing the carbonyls. Whenever the coating temperature was attained, a pressure of $\sim 133 \mathrm{~Pa}(1.0$ torr) was maintained by adjusting the valves between the flow meter and the pumping system.

Coating was conducted in a hot-wall reactor that had a (nickel-chromium wire-wound) heater outside the reaction tube. The temperature distribution, the position of the hot zone, and the placement of the stainless-steel substrate along the reaction chamber were carefully determined. The coating time was generally $10 \mathrm{~h}$. The coating temperature varied over the range of $175^{\circ}-450^{\circ} \mathrm{C}$, and a constant pressure of $\sim 133 \mathrm{~Pa}(1.0$ torr) was maintained.

\section{(3) Characterization}

The morphologies and thickness of the films were examined and measured directly using an SEM microscope (Model 515, Philips Research Laboratories, Eindhoven, The Netherlands) equipped for energy dispersive X-ray spectrometry (EDS) (Model 9100, EDAX International, Prairie View, IL). Crystalline phases were identified by using XRD (Model PW1729,
Philips Research Laboratories); the source was a nickel-filtered $\mathrm{Cu} K \alpha$ beam, and the operating voltage and current were $30 \mathrm{kV}$ and $20 \mathrm{~mA}$, respectively. The scan speed of the diffractometer was $0.05^{\circ}$ per second. XPS (Model PHI, ESCA-5400, PerkinElmer, Norwalk, CT) was used for semiquantitative chemical analysis, with $\mathrm{Ta}_{2} \mathrm{O}_{5}$ used as a reference material and multiple testing on the skin layer milled by an $\mathrm{Ar}^{+}$-ion beam up to a depth of $42 \mathrm{~nm}$. Corrosion resistance of the samples was determined by using the potentiodynamic scans technique with a potentiostat (Model 273A, Princeton Applied Research, Princeton, NJ). A standard Calomel electrode and $(1 M \mathrm{MaCl}+$ $1 \mathrm{M} \mathrm{H}_{2} \mathrm{SO}_{4}$ ) aqueous solution were used as a reference and medium, respectively. ${ }^{18}$ Scanning of the potentiostat started from $-0.6 \mathrm{~V}$ (referring to an equilibrium potential) to $1.2 \mathrm{~V}$ (referring to a reference electrode) with a scanning step of $1 \mathrm{mV} / \mathrm{s}$.

\section{Results}

The coating rate versus the reciprocal temperature is shown in Fig. 1(A). The dependency of the coating on the coating temperature is separated by two transitions at $\sim 400^{\circ}$ and $275^{\circ} \mathrm{C}$. At temperatures of $>400^{\circ} \mathrm{C}$, the coating rate is hardly measurable. At temperatures of $<400^{\circ} \mathrm{C}$, the rate increases as the temperature decreases, to attain a maximum value at $\sim 275^{\circ} \mathrm{C}$, and then decreases. These temperature regions are denoted hereafter as "high," "medium," and "low."

Density values of the films are calculated from the thickness and weight gain of films at various temperatures, as shown in Fig. 1(B). One density data point of the films, processed at $275^{\circ} \mathrm{C}$, could not be acquired because its morphology appeared to be layers of curling flakes. The density values of films appearing in Fig. 1(B) show a similar variation as in Fig. 1(A). The density of the films increases as the temperature increases in the low-temperature region. After it attains a maximum temperature of $\sim 275^{\circ} \mathrm{C}$, the coating rate value decreases as the coating temperature increases in the medium-temperature region.

The composition results of deposited films with the XPS technique are shown in Fig. 2. Figure 2(A) represents the typically elemental depth profiles of a film coated with the hexacarbonyls at $350^{\circ} \mathrm{C}$. The films contain oxygen and chromium in

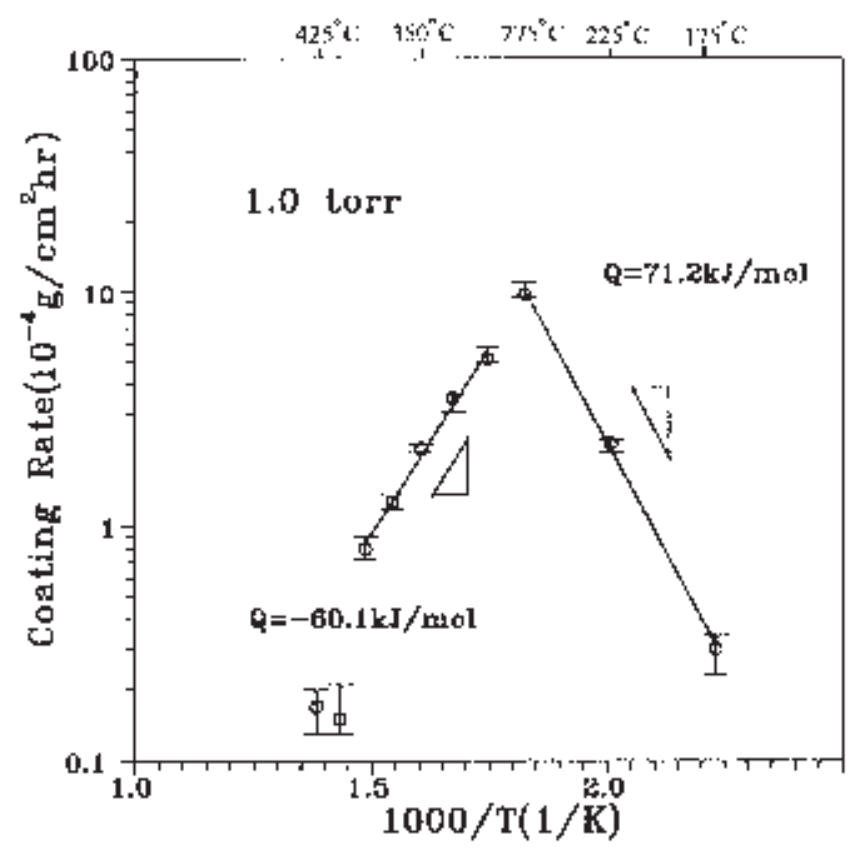

(A)

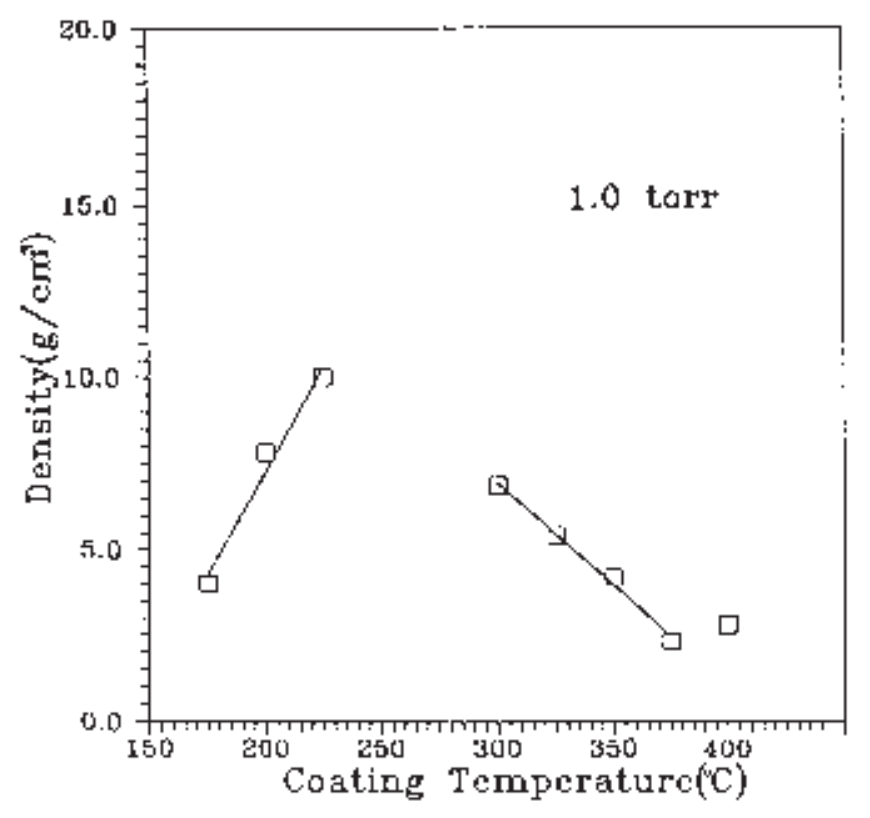

(B)

Fig. 1. (A) Plot of coating rate versus the reciprocal of coating temperature at a constant coating pressure of 1.0 torr; (B) the density of coated films, as a function of coating temperature. 


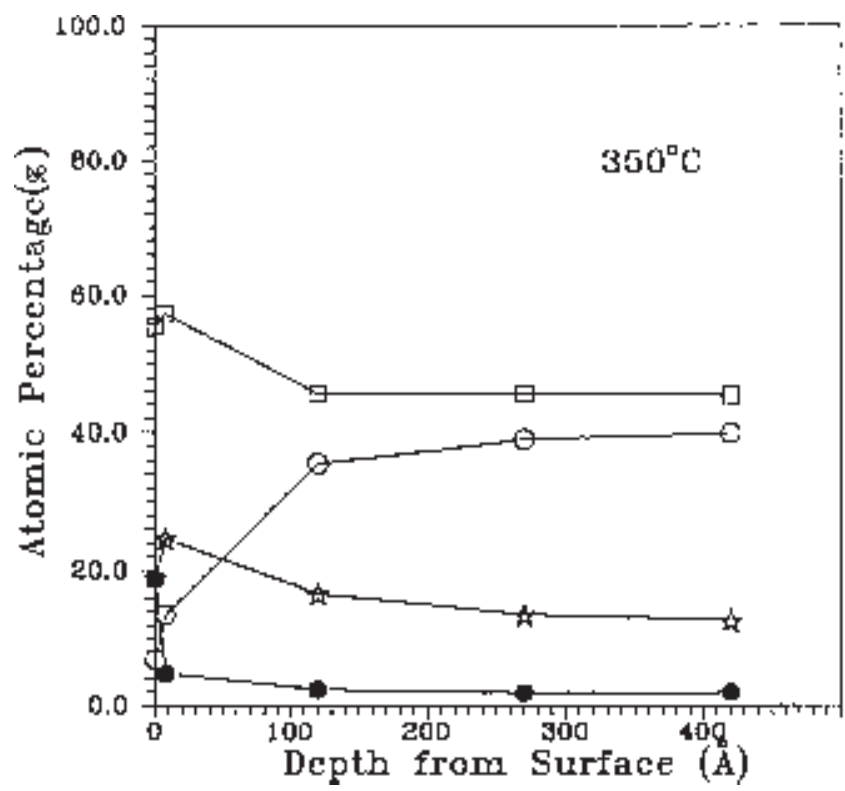

(A)

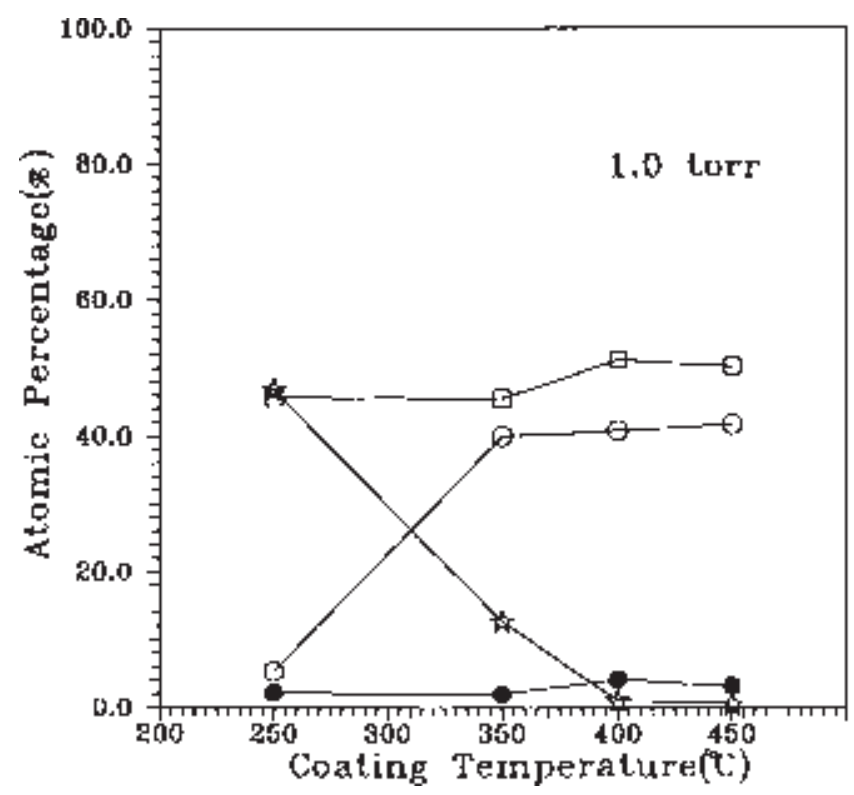

(B)

Fig. 2. (A) Typical depth profile of a composition for films prepared at $350^{\circ} \mathrm{C}$; (B) elemental constituents of deposited films obtained at various temperatures by MOCVD from a mixture of $\mathrm{Cr}(\mathrm{CO})_{6}$ and $\mathrm{Mo}(\mathrm{CO})_{6}(($ 论 $) \mathrm{Mo},(\mathrm{O}) \mathrm{Cr}$, (O) $\mathrm{C}$, and $(\square) \mathrm{O}$ ).

major amounts and molybdenum and carbon elements in minor amounts. The depth of profile from the surface shown in Fig. 2 is the sputtered depth of the reference material $\mathrm{Ta}_{2} \mathrm{O}_{5}$, rather than the thickness of the coated film.

Concentration distributions of the elements show a higher oxygen and carbon content near the film surfaces. Avoiding oxygenation on the surface of even the samples that had been kept in a vacuum chamber, which was first evacuated and then filled with nitrogen before the analyses, was difficult. Elemental concentration of the films becomes eonstant when a sputtered depth attains a value of $27 \mathrm{~nm}$ (270 A). As shown in Fig. 2(A), the curve becomes a plateau (the values are almost constant).
Therefore, the atomic percentages for each element, which are obtained at a sputtered depth of $42 \mathrm{~nm}(420 \mathrm{~A})$, are used to represent the concentration of the films obtained at different temperatures. The composition of four different films in various coating conditions has been analyzed in this way and is summarized in Fig. 2(B). In the figure, four samples are selected as the representatives of each temperature region: for the low- and medium-temperature regions, $250^{\circ}$ and $350^{\circ} \mathrm{C}$, respectively, were used; for the high-temperature region, $400^{\circ}$ and $450^{\circ} \mathrm{C}$ were used.

Four XRD results are shown in Fig. 3. Three represent the typical patterns of films that are obtained in high- $\left(450^{\circ} \mathrm{C}\right)$,

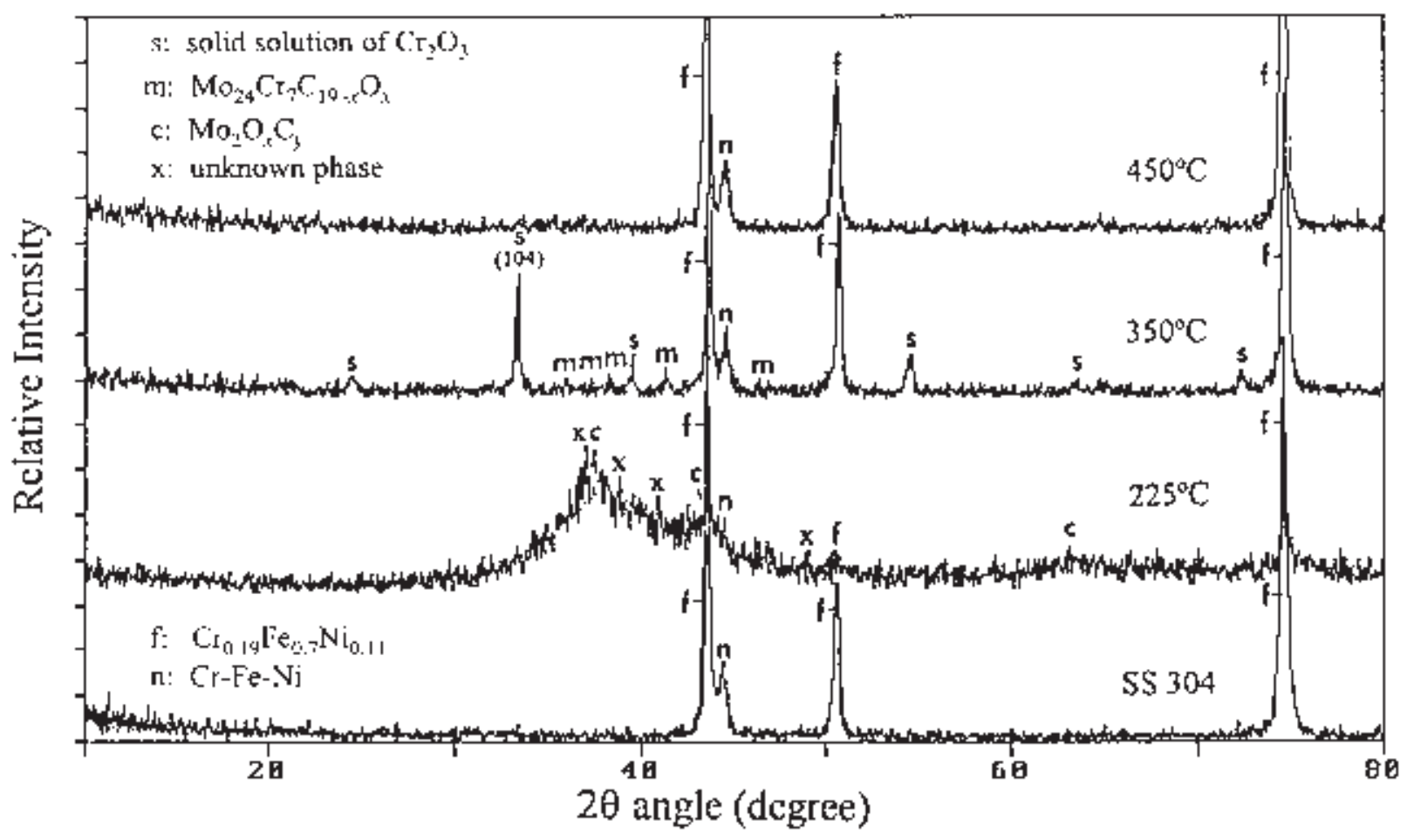

Fig. 3. Three typical XRD patterns of deposited films obtained at various coating temperatures and one XRD pattern of a stainless-steel substrate. 

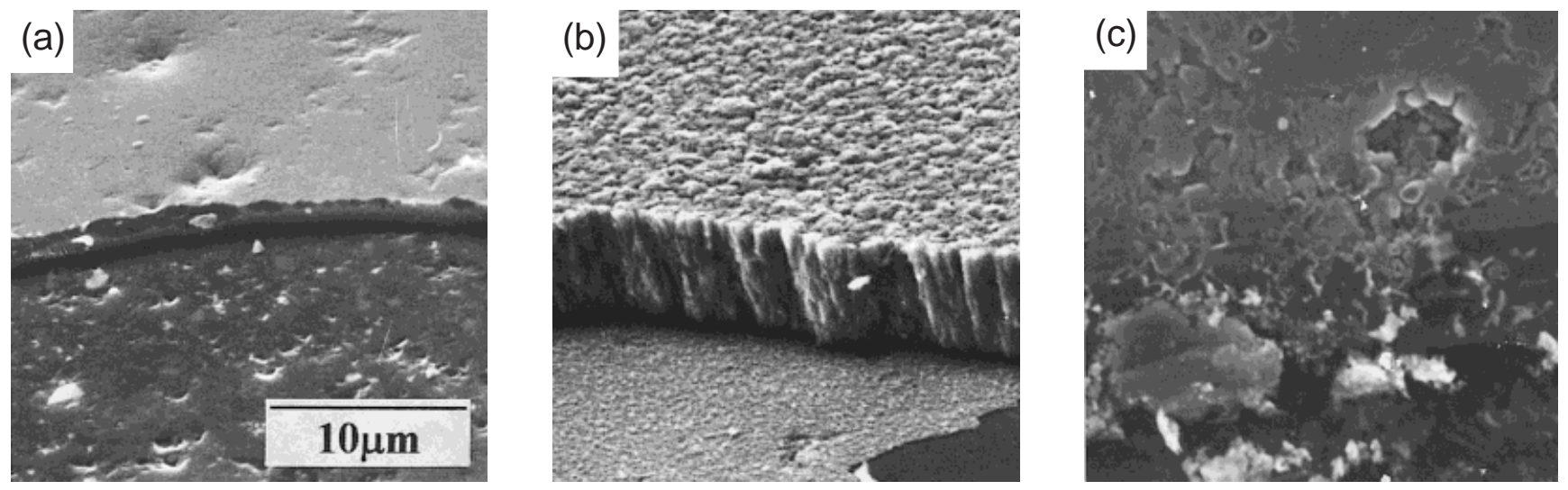

Fig. 4. SEM micrographs illustrating typical morphologies of films processed in (A) low-, (B) medium-, and (C) high-temperature regions.

medium- $\left(350^{\circ} \mathrm{C}\right)$, and low-temperature $\left(225^{\circ} \mathrm{C}\right)$ regions; the pattern of the SS 304 substrate also is shown. The film that is obtained at a temperature of $350^{\circ} \mathrm{C}$ is mainly composed of two phases, which have structures similar to $\mathrm{Cr}_{2} \mathrm{O}_{3}$ and $\mathrm{Mo}_{24} \mathrm{Cr}_{7} \mathrm{C}_{19}$, whereas the film obtained at a temperature of $225^{\circ} \mathrm{C}$ is composed of two other phases: the major one is $\mathrm{Mo}_{2} \mathrm{O}_{x} \mathrm{C}_{y}$, and the minor one is possibly a $\mathrm{Cr}_{3} \mathrm{C}_{2}$ phase (indicated as an unknown phase in Fig. 3) with a very fine crystallite size. No crystalline phases are found for the film that is deposited at a temperature of $450^{\circ} \mathrm{C}$, because it could be amorphous or too thin to be detected by XRD.

The morphologies of the films are demonstrated in Fig. 4, where Figs. 4(A), (B), and (C) are the films processed at low, medium, and high temperatures, respectively. The edges of coated films were produced by scratching films with a diamond tip. Systematic analyses of the microstructure will be reported elsewhere. $^{19}$

Potentiodynamic scans for the SS 304 plate and the samples with coated films were obtained, as shown in Fig. 5. Corrosion current densities of the samples from the deposition at $225^{\circ}$, $350^{\circ}$, and $450^{\circ} \mathrm{C}$ were determined from the curves in Fig. 5 by the Tafel method. ${ }^{10}$ The corrosive current densities of the SS 304 plate (closed circle) and the samples with oxycarbide films (open circles), as a function of the coating temperature, are shown in Fig. 6. The smaller current density represents a superior corrosion resistance. The anticorrosion properties of the samples that are processed at low and medium temperatures are better than the substrate, whereas films that are obtained at high temperature are detrimental for corrosion protection. Results of this work are briefly summarized in Table I.

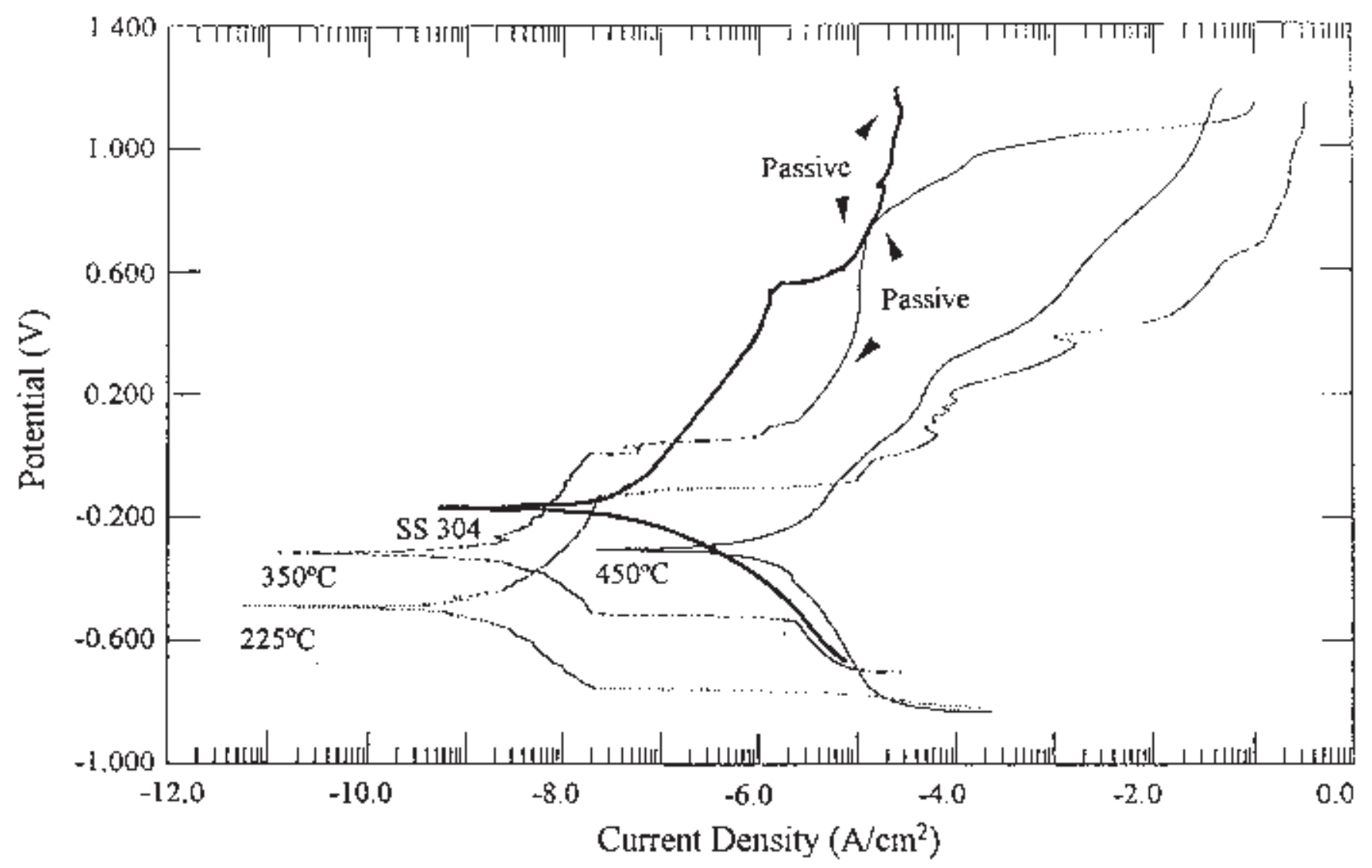

Fig. 5. Potentiodynamic scans of SS 304 and samples coated with oxycarbide films processed at different temperatures. Note that passive protection is found in some sections of the curves. 


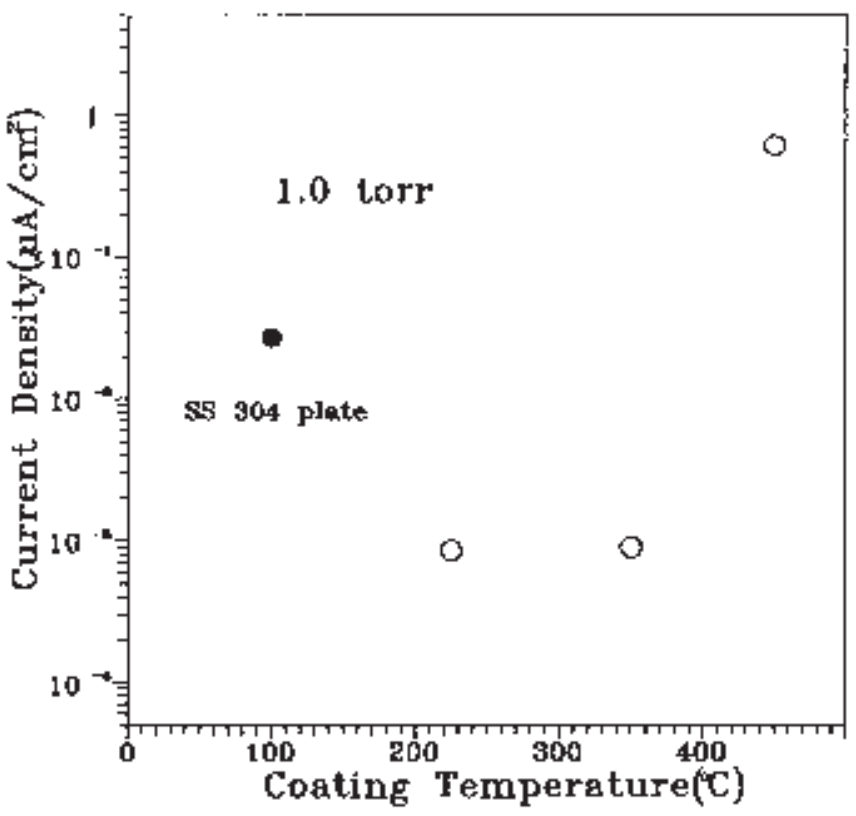

Fig. 6. Corrosive current density of films determined from the curves of potentiodynamic scans for the films deposited in varied temperature regions.

\section{Discussion}

\section{(1) Controlling Mechanism of Coating Process}

Shaw $^{20}$ and Matthews and Rickerby ${ }^{21}$ have extensively reviewed the general relationship between the dependence of the coating rate on temperature and controlling mechanisms in the process of vapor-phase coating. They reported four typical reaction steps occurring in the MOCVD processes. Two of the steps-transport of reactants and depletion of excessive products through a laminar layer-are diffusion processes. The diffusion types of this experimental work were determined to be ordinary diffusion. ${ }^{22}$ The diffusion coefficients of the ordinary diffusion were then computed and substituted in the following equation (Eq. (1)) to estimate the diffusion flux. ${ }^{23}$ The flux $\left(J_{D}\right)$ of vapor molecules for deposition, according to the boundarylayer model, is

$$
J_{D}=\frac{2.68 D C_{0}}{h \exp \left(\frac{-2.84 D z}{h^{2} v_{0}}\right)}
$$

where $C_{0}$ is the initial concentration, $h$ the reactor height, $z$ the distance from the position where the concentration is $0.99 C_{0}$ to the substrate, and $v_{0}$ the initial flow velocity. An approximate value of $z$ is used, equal to the distance from the entrance of the tube reactor to the substrate.

The values of $J_{D}$ from the above equation for each test condition appear to be infinitely large, which means that the vapor molecules are sufficiently supplied to the surface of substrates under all deposition conditions. Because the coating pressure of this coating process is so low ( $\sim 133 \mathrm{~Pa}$ (1.0 torr)), the boundary layer formed by laminar flow is negligible. This consequence shows that the diffusion process (the second and fourth steps) are not the controlling step within the testing temperature region.
Considering the controlling mechanism at a low temperature to be a thermal-activated process, the apparent activation energy was determined to be $71.2 \pm 3.8 \mathrm{~kJ} / \mathrm{mol}$ in the low-temperature region. Similarly, the value of the activation energy was $-60.1 \pm 4.5 \mathrm{~kJ} / \mathrm{mol}$ for a medium-temperature coating. However, the activation energies for mechanisms controlled by mass transport (diffusion) or thermodynamics (evaporation) are usually $<20 \mathrm{~kJ} / \mathrm{mol} .{ }^{21}$ The higher values of the activation energies in this study suggest that the coating process is controlled by neither diffusion nor evaporation steps.

Another fact is that the evaporation rate is always larger than the pyrolysis rate within the coating-temperature regions. The evaporation rate that is calculated from the weight loss of precursor powder is $1.13 \times 10^{15} \mathrm{~s}^{-1}$, whereas pyrolysis rates have been determined to be in the range of $1.16 \times 10^{12}-2.32 \times 10^{13}$ $\mathrm{s}^{-1}$ for temperatures in the range of $175^{\circ}-450^{\circ} \mathrm{C} .^{24,25}$ It can be concluded that the evaporation is not the controlling step. Therefore, the possible controlling mechanisms of the coating process in consideration are pyrolysis and surface reaction.

$\mathrm{Baev}^{24}$ thoroughly documented the kinetics of thermal decomposition (pyrolysis) for the mixtures of various carbonyls under similar conditions as in this study. He found that the activation energy of the pyrolysis of various $\mathrm{Mo}(\mathrm{CO})_{6}$ and $\mathrm{Cr}(\mathrm{CO})_{6}$ mixtures was dependent on their composition. The pyrolytical $\mathrm{CO}$ groups from each carbonyl seemed to affect the pyrolysis rate of the other in the mixture. The activation energy for the composition used in this study was reported to be 53.2 $\mathrm{kJ} / \mathrm{mol},{ }^{24}$ which is lower than the activation energy of the coating measured in Fig. 1(A). This information implies that pyrolysis is not the controlling mechanism. Consequently, the possible controlling mechanism of this coating process could only be the surface reaction.

On the other hand, Matthews and Rickerby ${ }^{21}$ summarized the differences of dependence of Arrhenius plots between the processes controlled by an endothermic or exothermic surface reaction. The dependence of the coating rate on the reciprocal temperature in Fig. 1(A) is found to correspond to a CVD process that is controlled by an exothermic surface reaction. The main difference of the curves reported in the Matthews and Rickerby work ${ }^{21}$ with this study is that the transition of the mass-transport-controlled region disappeared. Because the reactants shown previously are sufficiently transported to the reaction surface during the deposition reactions, the elimination of the mass-transport-controlled region is reasonable.

The possible surface reactions are discussed as follows. After pyrolysis, the produced species include $\mathrm{Mo}, \mathrm{Cr}$, and $\mathrm{CO}$. However, Shinn and Madey ${ }^{26}$ reported that the $\mathrm{CO}$ molecules at low temperatures were unstable and had a tendency to chemisorb onto the surface of transit metals. The bond between carbon and oxygen would break when the chemisorption occurred. This reaction occurs extensively during the coating process ${ }^{27}$ and indicates that the possible reaction species of the surface reaction are $\mathrm{Mo}, \mathrm{Cr}, \mathrm{Mo}-\mathrm{C}, \mathrm{Cr}-\mathrm{C}$, and $\mathrm{O}$. On the other hand, the results of XRD show that the products of surface reaction (coatings) are $\mathrm{Mo}_{2} \mathrm{O}_{x} \mathrm{C}_{y}, \mathrm{Mo}_{24} \mathrm{Cr}_{7} \mathrm{C}_{19}$, and a solid solution of $\mathrm{Cr}_{2} \mathrm{O}_{3}$, etc. The yield of these products from the abovementioned reactants is related to the construction of bonds and should accompany the release of heat, which supports the point that the surface reactions are exothermic.

\section{(2) Evolution of Density, Chemical Composition, and} Phases

Two points can be noticed in Fig. 1(B): the densities of coated films that are obtained at a different condition are not

Table I. Summary of the Coating Process and the Properties of Deposited Films in This Work

\begin{tabular}{clcccc}
\hline Temperature & \multicolumn{1}{c}{ Density $\left(\mathrm{g} / \mathrm{cm}^{3}\right)$} & $\begin{array}{c}\text { Activation energy } \\
(\mathrm{kJ} / \mathrm{mol})\end{array}$ & $\begin{array}{c}\text { Atomic ratio, } \\
\mathrm{Cr} /(\mathrm{Mo}+\mathrm{Cr})\end{array}$ & Phase(s) present & Corrosion protection \\
\hline High $\left(450^{\circ}-400^{\circ} \mathrm{C}\right)$ & $2.75( \pm 0.15)$ & & 0.96 & $\mathrm{Cr}_{2} \mathrm{O}_{3}$ & $\mathrm{Detrimental}$ \\
Medium $\left(400^{\circ}-300^{\circ} \mathrm{C}\right)$ & $2.3( \pm 0.2)-6.8( \pm 0.4)$ & $-60.1( \pm 0.5)$ & 0.76 & $(\mathrm{Mo}, \mathrm{Cr})_{2}(\mathrm{C}, \mathrm{O})_{3}, \mathrm{Mo}_{24} \mathrm{Cr}_{7}(\mathrm{C}, \mathrm{O})_{19}$ & $\mathrm{Superior}_{2}$ \\
Low $\left(275^{\circ}-175^{\circ} \mathrm{C}\right)$ & $4.0( \pm 0.2)-10.0( \pm 0.5)$ & $71.2( \pm 3.8)$ & 0.10 & $\mathrm{Mo}_{2} \mathrm{O}_{x} \mathrm{C}_{y}$, unknown phase & $\mathrm{Improved}$ \\
\hline
\end{tabular}


constant, and the variation of density with temperature is consistent with the dependency of the coating rate on temperature. For the study of the coating process,$^{20}$ one unit of the coating rate-growth thickness per unit time per specific area-was frequently used in literature. The usage of this unit for the presentation of the complex $(\mathrm{Mo}, \mathrm{Cr})$ oxycarbide coating system, we think, is inappropriate, because the density of the coated films in different process conditions is not the same at all. Therefore, the unit used in this work was weight gain per unit time per specific area.

The density of films may change with the types of deposited phases, the porosity in film, or the relative fraction of composed phases. The consistency of density and coating rate on the coating temperature results from the difference in crystalline phases (Table I).

Singmaster et $a l .{ }^{27}$ systematically studied the chemical compositions of the deposited films that were prepared from metal carbonyls by a photochemical method in different vacuum states, especially the carbon and oxygen contents on the surface and in bulk. They found that newly deposited films exposed to air resulted in a significant oxidation through the entire thickness, even though the exposure time was only $30 \mathrm{~min}$. Simultaneously, this oxidation caused a segregation of carbon on the film surface and was not prohibited by the oxygen content of the film. Therefore, the formation of $\mathrm{CO}$ or $\mathrm{CO}_{2}$ on the film surface would induce a partial loss of the carbon content in the film. For the films prepared by MOCVD, similar phenomena were found in this work. Our chemical analysis (Fig. 2(A)) of the deposited film shows higher concentrations of oxygen and carbon near the film surface. This implies that the carbon content of the film reported in the profile (Fig. 2(B)) may be lower than that of a newly deposited film.

Additionally, the concentration of chromium noticeably increases as the temperature increases and the chromium: oxygen atomic ratio of samples at temperatures of $400^{\circ}$ or $450^{\circ} \mathrm{C}$ is very close to $2: 3$, which strongly suggests that the main composition of the films that are deposited in the hightemperature region is $\mathrm{Cr}_{2} \mathrm{O}_{3}$. On the other hand, the molybdenum concentration decreases as the temperature increases. The concentrations of oxygen and carbon remain almost constant through the entire temperature range of the deposition.

Because the original concentration of $\mathrm{Cr}(\mathrm{CO})_{6}$ is known to be 10 mass $\%$ in the precursory admixture, the relative ratio of $\mathrm{Cr} /(\mathrm{Mo}+\mathrm{Cr})$ is equal to 0.12 in the source powder. Nevertheless, the relative ratios of $\mathrm{Cr} /(\mathrm{Mo}+\mathrm{Cr})$ in these films are 0.10 , $0.76,0.98$, and 0.96 for samples that are processed at temperatures of $250^{\circ}, 350^{\circ}, 400^{\circ}$, and $450^{\circ} \mathrm{C}$, respectively; this reveals that, as the coating temperature increases, the deposition of the $\mathrm{Cr}$ species becomes dominant during the deposition. As illustrated in Fig. 2(B), the concentration of molybdenum at a high temperature is so low that the main constituents of the film are primarily chromium and oxygen. Because the molecular weight and diffusion volume of chromium are smaller than molybdenum, the temperature dependency of diffusivity of atomic chromium is greater than that of molybdenum. Consequently, the concentration of chromium in Mo-Cr-O-C vapor above the substrate increases as the temperature increases. This change of gaseous composition will cause the selective adsorption of metallic atoms ${ }^{28}$ and consequent reactions, such as a chemisorption of COs or a breakage of $\mathrm{CO}$ bonds, etc.

Because the controlling mechanism had been indicated to be surface reaction, the result of the coating rate strongly suggests that a switching of the dominating reaction or preference of depositing products occurs between low- and mediumtemperature regions. The variation of the dominant reaction of gaseous chromium compositions via the change of coating temperature is the main reason for the switching in the coating rate and density, composition, and deposited phases with the coating temperature. This also means that the deposition rate of products from chromium is slower than the products from molybdenum.
A chemical formula, $\mathrm{Mo}_{24} \mathrm{Cr}_{7}(\mathrm{C}, \mathrm{O})_{19}$, which is a solid solution of carbon and oxygen, is proposed to represent the phase of solid solution of $\mathrm{Mo}_{24} \mathrm{Cr}_{7} \mathrm{C}_{19}$, according to the chemical result shown in Fig. 2(B). The proposed phase has an identical crystalline structure and similar chemistry to $\mathrm{Mo}_{24} \mathrm{Cr}_{7} \mathrm{C}_{19}$. In addition, we found that the chromium peak was shifting from that of pure chromium carbide in the XPS spectra of the films $\left(350^{\circ} \mathrm{C}\right)$, and the binding energy of the chromium in $\mathrm{Mo}_{24}$ $\mathrm{Cr}_{7}(\mathrm{C}, \mathrm{O})_{19}$ is actually in a state of $-\mathrm{Cr}-\mathrm{O}_{x}$, not a pure carbide. The other crystalline phase in the medium-temperature region has a $\mathrm{Cr}_{2} \mathrm{O}_{3}$ structure. However, the intensity of the XRD spectrum (in Fig. 3) is very strong at its (104) peak, implying that the crystals grow with (104) as a preferential plane. Besides, a careful comparison of peaks of $\mathrm{Cr}_{2} \mathrm{O}_{3}$ in the ICDD files (file card number 38-1479) reveals that the $d$-spacing of the detected oxide phase is larger than that of the standard. The results suggest that one of the crystalline phases of the films that are processed at a temperature of $350^{\circ} \mathrm{C}$ contains a $(\mathrm{Mo}, \mathrm{Cr})_{2}(\mathrm{C}, \mathrm{O})_{3}$ composition with molybdenum in solid solution.

The phase molybdenum oxycarbide, $\mathrm{Mo}_{2} \mathrm{O}_{x} \mathrm{C}_{y}$, is the product that is frequently obtained from molybdenum carbonyl by the MOCVD process. The XRD results (Fig. 3) depict that $\mathrm{Mo}_{2} \mathrm{O}_{x} \mathrm{C}_{y}$ and unknown phases in the films are obtained at a low deposition temperature. The $\mathrm{Mo}_{2} \mathrm{O}_{x} \mathrm{C}_{y}$ phase has been reported by Ferguson et al. ${ }^{17}$ and appears to have an XRD pattern similar to that of $\mathrm{Mo}_{2} \mathrm{C}$ (face-centered cubic structure). Ferguson et al. ${ }^{17}$ showed that the composition might vary from $\mathrm{Mo}_{2} \mathrm{C}_{0.7} \mathrm{O}_{0.6}$ to $\mathrm{Mo}_{2} \mathrm{C}_{0.6} \mathrm{O}_{0.5}$. However, the XRD peaks (Fig. 3) of the samples that were processed at a temperature of $225^{\circ} \mathrm{C}$ in this study show broader diffraction angles $(2 \theta)$ than any previous phases, e.g., $\mathrm{Cr}_{2} \mathrm{O}_{3}$. The broadening of $\mathrm{X}$-ray peaks is normally due to fine grains that are distributed in the matrix. The $\mathrm{Mo}_{2} \mathrm{O}_{x} \mathrm{C}_{y}$ grains near the interface of the substrate, observed by highresolution transmission electron microscopy (HRTEM), appeared to be tens of nanometers in size. The detailed microstructural analysis will be reported in our next paper.

The theoretical densities of $\mathrm{Mo}_{2} \mathrm{O}_{x} \mathrm{C}_{y}$ are $2.88 \pm 0.15 \mathrm{~g} / \mathrm{cm}^{3}$. Although the density of the films varies from $4.0 \pm 0.02$ to $10.0 \pm 0.5 \mathrm{~g} / \mathrm{cm}^{3}$ in the low-temperature region, as shown in Fig. 1(B), the maximum density of the films is larger than the density of $\mathrm{Mo}_{2} \mathrm{O}_{x} \mathrm{C}_{y}$. In addition, the SEM morphology of the films from a low-temperature region shows a dense and smooth surface (Fig. 4(A)), which suggests that the density of the above-mentioned unknown phase may be $>10.0 \pm 0.5 \mathrm{~g} / \mathrm{cm}^{3}$.

For the films that are obtained in a high-temperature region, the chromium:oxygen atomic ratio is $2: 3$, as analyzed by XPS in Fig. 2(B). Therefore, the composed phase of this film is a $\mathrm{Cr}_{2} \mathrm{O}_{3}$ whose theoretical density is $5.23 \mathrm{~g} / \mathrm{cm}^{3}$. A low density $\left(2.75 \pm 0.15 \mathrm{~g} / \mathrm{cm}^{3}\right)$ of the film that is obtained at high temperature $\left(>400^{\circ} \mathrm{C}\right)$ seems to disclose the porous character of the layers. As shown in Fig. 4(C), a loose morphology of the film is evident.

\section{(3) Corrosion Resistance}

Obviously, the electric current density of the samples (Figs. 5 and 6) that are obtained at low or medium temperatures is smaller than that of SS 304. The improvement factor of corrosion resistance from the presence of oxycarbide films is $\sim 24$. The absolute value of current density for SS 304 is somewhat lower, because its surface was polished before testing. The current density attained in this study, $2.1 \times 10^{-5} \mu \mathrm{A} / \mathrm{cm}^{2}$, is much smaller than the value of $2.0 \mu \mathrm{A} / \mathrm{cm}^{2}$, which is the current density of an as-sintered SS $304,{ }^{29}$ however, the current density of the sample that is obtained at a high temperature $\left(450^{\circ} \mathrm{C}\right)$ is larger than that of the substrate. Although the films that are obtained in the high-temperature region have the same phase as a chromium-oxide protective layer of a corroded SS 304, the corrosion resistance is much smaller than that of an SS 304 plate; this may be caused by a pitting corrosion on

International Center for Diffraction Data, Newtowne Square, PA. 
the porous film that is obtained at a high temperature and, hence, degradation in the corrosion resistance of the SS 304 plate at a factor of 28. Notably, the protective layer that is essentially formed on the stainless steel is dense, whereas the film that is formed from the MOCVD process at temperatures of $>400^{\circ} \mathrm{C}$ is porous.

Further investigation on the potentiodynamic scan curve in Fig. 5 reveals that only the film that is obtained at a medium temperature and the SS 304 plate perform the effect of passive protection, as one section of the curve highlights in the figure. The current densities of passive corrosion of these two samples are 10 and $20 \mu \mathrm{A} / \mathrm{cm}^{2}$, respectively. The results indicate that the film at a medium temperature is the best candidate for the improvement of corrosion resistance of stainless steel in an environment with chloride and sulfuric acids.

The corrosive protections of the films by MOCVD correlate less with the composition, density, and thickness of the films but closely relate to the crystalline phases and the intactness of the films. Because the corrosion resistance of stainless steel is produced by the formation of a protective layer of $\mathrm{Cr}_{2} \mathrm{O}_{3}$, the improvement of corrosion resistance of the best protective oxycarbide film should, therefore, be produced by either the protection of $\mathrm{Mo}_{24} \mathrm{Cr}_{7}(\mathrm{C}, \mathrm{O})_{19}$, and/or $(\mathrm{Mo}, \mathrm{Cr})_{2}(\mathrm{C}, \mathrm{O})_{3}$, which might induce similar protection mechanisms as stainless steel.

Weil and Sheu ${ }^{30}$ demonstrated that the chromium films with either molybdenum or carbon content had superior or better corrosion resistance, respectively, than that of the single-layer coatings of chromium for the corrosion of sulfuric acid. We believe that the films prepared by Weil and Sheu ${ }^{30}$ are oxidized. It is likely that both composed phases, two solid-solution phases, $(\mathrm{Mo}, \mathrm{Cr})_{2}(\mathrm{C}, \mathrm{O})_{3}$, and $\mathrm{Mo}_{24} \mathrm{Cr}_{7}(\mathrm{C}, \mathrm{O})_{19}$ of the best protective film that is obtained at a medium temperature have similar phases as those in the Weil and Sheu ${ }^{30}$ work. Therefore, the protective effect in both cases should be the same.

In the meantime, the improvement of the corrosion resistance of the films that are obtained in the low-temperature region, which consists of $\mathrm{Mo}_{2} \mathrm{O}_{x} \mathrm{C}_{y}$ and an unknown phase, is evident and is contributed by an intact, nonporous film with an appropriate composition. No similar reports about the corrosion resistance of $\mathrm{Mo}_{2} \mathrm{O}_{x} \mathrm{C}_{y}$ are found in the literature; however, the corrosion resistance of the film is appreciable.

\section{Conclusion}

Films that were prepared by MOCVD from the hexacarbonyl sources of chromium and molybdenum were obtained and investigated. Improvement of corrosion resistance for stainless steel by the films that formed at various temperatures was examined. The relationship between their corrosion resistance and properties including density, composition, and formation of crystalline phases is summarized in Table I. The results are briefly concluded below.

In regard to the deposition kinetic, including diffusion, evaporation and pyrolysis, and the dependency of the coating rate on the coating temperature, the results demonstrate that the coating processes are controlled by exothermic surface reactions. Detailed analyses of the densities and composition of the films reveal that the dominating reactions will change with gaseous composition as temperatures increase. Chromium content in the gas becomes dominating at a higher temperature, while the deposition rate decreases. This change causes the dependency of deposition rate, the densities, the compositions, and the phases of the deposited films to vary accordingly.

Phase analyses by XRD show that composed phases of the films that are obtained in medium-temperature regions are $(\mathrm{Mo}, \mathrm{Cr})_{2}(\mathrm{C}, \mathrm{O})_{3}$ and $\mathrm{Mo}_{24} \mathrm{Cr}_{7}(\mathrm{C}, \mathrm{O})_{19}$; however, $\mathrm{Mo}_{2} \mathrm{O}_{x} \mathrm{C}_{y}$ and an unknown phase are produced in a low-temperature region. The films of low and medium temperatures improved the corrosion resistance of SS 304 by a factor of 24 . The film that is obtained in a high-temperature region, which consists of a porous $\mathrm{Cr}_{2} \mathrm{O}_{3}$ phase, is detrimental in the corrosion of the material. Among these, only the film that is obtained in a mediumtemperature region has the effect of passive protection and seems to be the best candidate for the purpose of the improvement of corrosion resistance.

\section{References}

${ }^{1}$ H. Kraute, H. Rohle, A. Escoboea, and H. Benking, "Investigation on Low Temperature MOCVD Growth of GaAs," J. Electron. Mater., 12, 215-22 (1983).

${ }^{2}$ M. Mizuta, T. Iwamoto, F. Moriyama, S. Kawata, and H. Kukimoto, "AlGaAs Growth Using Trimethyl and Triethyl Compound Sources," J. Cryst. Growth, 68, 142-47 (1984).

${ }^{3}$ C. Plass, H. Heinecke, O. Kayser, H. Luth, and P. Balk, "A Comparative Study of $\mathrm{Ga}\left(\mathrm{CH}_{2}\right)_{3}, \mathrm{Ga}\left(\mathrm{C}_{2} \mathrm{H}_{5}\right)_{3}$ and $\mathrm{Ga}\left(\mathrm{C}_{4} \mathrm{H}_{9}\right)_{3}$ in the Low Pressure MOCVD GaAs," J. Cryst. Growth, 88, 455-64 (1988).

${ }^{4}$ J. J. Lander and L. H. Germer, "Plating Molybdenum, Tungsten and Chromium by Thermal Decomposition of Their Carbonyls," Met. Technol. (NY) (Technical Publication 2259, Classes C and E), 14 [6] 1-42 (1947).

${ }^{5}$ D. Bauerle, "Material Deposition"; pp. 69-134 in Springer Series Materials Science, Vol. 1, Chemical Processing with Laser. Springer-Verlag, Berlin, Heidelberg, FRG, 1986.

${ }^{6}$ M. Kmetz, S. L. Suib, and F. S. Galasso, "Processing of Molybdenum Oxycarbide Coating," J. Am. Ceram. Soc., 72 [8] 1523-24 (1989).

${ }^{7}$ M. Kmetz, B. J. Tan, W. Willis, S. Suib, and F. S. Galasso, "CVD Mo, W and Cr Oxycarbide, Carbide and Silicide Coatings on SiC Yarn," J. Mater. Sci., 26, 2107-10 (1991).

${ }^{8}$ W. Radloff, H. Hohmann, H. H. Ritze, and R. Paul, "Excimer Laser Photolysis of Molybdenum Hexacarbonyl with Buffer Gas," Appl. Phys. B, 49, $301-$ 305 (1989).

${ }^{9}$ N. Okada, Y. Katsumura, and K. Ishigure, "Modeling of Gas Phase Process in Laser-induced Chemical Vapor Deposition from $\mathrm{Cr}(\mathrm{CO})_{6}$ with An Excimer Laser," Appl. Phys. A, 56, 138-46 (1993).

${ }^{10}$ A. J. Sedriks, "Effect of Environment"; pp. 81-84 in Corrosion of Stainless Steels. Wiley, New York, 1979.

${ }^{11}$ P. D. Hicks and F. P. A. Robinson, "The Aqueous Corrosion Behavior of an Ion Implanted 12\% Chromium Steel," Corros. Sci., 24, 885-900 (1984).

${ }^{12}$ P. M. Natishan, E. McCafferty, and G. K. Hubler, "The Corrosion Behavior of Mo-Al, Cr-Al and Cr-Mo-Al Surface Alloys Produced by Ion Beam Mixing and Ion Implantation," Corros. Sci., 32, 721-31 (1991).

${ }^{13}$ R. F. Bunshah, "Deposition Technologies: An Overview"; pp. 1-18 in Deposition Technologies for Films and Coatings. Edited by R. F. Bunshah. Noyes, Park Ridge, NJ, 1982.

${ }^{14}$ N. Okada, Y. Katsumura, and K. Ishigure, "Improvement of Corrosion Resistance of Carbon Steel Using Chemical Vapor Deposition from the Mixture of $\mathrm{Mo}(\mathrm{CO})_{6}$ and $\mathrm{Cr}(\mathrm{CO})_{6}$ with An Ar-F Excimer Laser," Appl. Phys. A, 58, 99 105 (1994).

${ }^{15}$ D. R. Lide, "Physical Constants of Inorganic Compounds"; pp. 4-76 in Handbook of Chemistry and Physics, 72nd ed. CRC Press, Boston, MA, 199192.

${ }^{16}$ W. J. McCreary, "Microspherical Laser Targets by CVD"; pp. 714-25 in Proceedings of the 5th International Conference on CVD. Edited by J. M. Blocher Jr., H. H. Hinterman, and L. H. Hall. The Electrochemical Society, Princeton, NJ, 1975.

${ }^{17}$ I. F. Ferguson, J. B. Hinseough, D. Morse, and A. W. Miller, "Decomposition of Molybdenum Hexacarbonyl,” Nature (London), 202, 1327 (1964).

${ }^{18}$ Y. Liang, J. Wang, B. Tong, and Z. Si, "Microstructure and Corrosion Resistance of Laser Surface Alloying Plasma Sprayed Cr-Mo Coating," Acta Metall. Sinica, Series A, 5, 261-65 (1992).

${ }^{19}$ M.-H. Lo and W. J. Wei, "Microstructure and Surface Properties of (Cr,Mo) Oxycarbide Grown on Stainless Steel via MOCVD," J. Mater. Res., 11 [11] 2895-902 (1996).

${ }^{20}$ D. W. Shaw, "Mass Transport-Type II or Diffusion Control"; pp. 24-28 in Crystal Growth, Theory \& Techniques, Vol. 1. Plenum, New York, 1974.

${ }^{21}$ A. Matthews and D. S. Rickerby, "Thermally Activated Chemical Vapor Deposition"; pp. 177-87 in Advanced Surface Coating: A Handbook of Surface Engineering. Chapman and Hall, New York, 1991.

${ }^{22}$ G. B. Stringfellow, "Approximate Analytical Approach for OMVPE Reactors"; pp. 226-30 in Organometallic Vapor-Phase Epitaxy, Theory and Practice. Academic Press, New York, 1989.

${ }^{23}$ M.-H. Lo, "Investigation on Process and Properties of Coatings from Molybdenum and Chromium Carbonyls"; Ph.D. Thesis. National Taiwan University, Taipei, Taiwan, ROC, June 1997.

${ }^{24}$ A. K. Baev, "Kinetics of Thermal Decomposition of Chromium and Molybdenum Hexacarbonyls," Zh. Fiz. Khim., 67 [8] 1607-10 (1993).

${ }^{25}$ K. E. Lewis, D. M. Golden, and G. P. Smith, "Organometallic Bond Dissociation Energies: Laser Pyrolysis of $\mathrm{Fe}(\mathrm{CO})_{5}, \mathrm{Cr}(\mathrm{CO})_{6}, \mathrm{Mo}(\mathrm{CO})_{6}$ and $\mathrm{W}(\mathrm{CO})_{6}$," J. Am. Chem. Soc., 106, 3905-12 (1984).

${ }^{26}$ N. D. Shinn and T. E. Madey, "CO Chemisorption on $\mathrm{Cr}(110)$ : Evidence for a Precursor to Dissociation,” J. Chem. Phys., 83 [11] 5928-35 (1985).

${ }^{27}$ K. A. Singmaster, F. A. Houle, and R. J. Wilson, "Photochemical Deposition of Thin Films from the Metal Hexacarbonyls," J. Phys. Chem., 94, 686475 (1990).

${ }^{28}$ J. M. Thomas and W. J. Thomas, "Adsorption Isotherms"; pp. 32-41 in Introduction to the Principles of Heterogeneous Catalysis. Academic Press, London, U.K., 1975.

${ }^{29}$ G. H. Lei and R. M. German, "Corrosion of Sintered Stainless Steels in a Sodium Chloride Solution," Mod. Dev. Powder Metall., 16, 261-75 (1985).

${ }^{30}$ R. Weil and C. Sheu, "Properties of Composite Electrodeposits," Final Report, Army Research Office, July '87-Aug. '90, Research Triangle Park, NC, 1990. 